
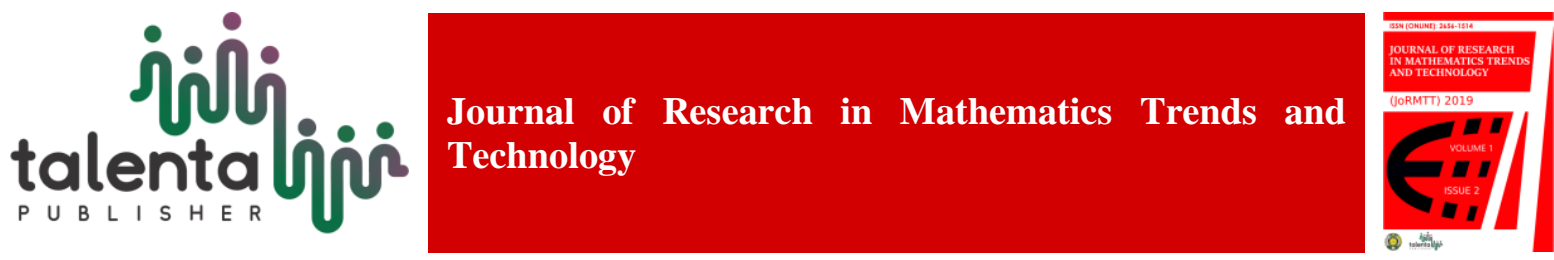

\title{
Some Vector Valued Sequence Spaces Generated by Musielak-Phy Function Over 2-Normed Spaces
}

\section{Ofie ${ }^{1}$ and M K M Nasution ${ }^{2 *}$}

${ }^{1}$ Department of Mathematics, Institut Teknologi Bandung, Bandung, 40132, Indonesia

${ }^{2}$ Department of Information Technology, Universitas Sumatera Utara, Medan, 20155, Indonesia

\begin{abstract}
In this work, we introduced some new vector valued sequence spaces over 2normed spaces using Musielak-Phy function $\Phi=\left(\varphi_{n}\right)$. We also studied some properties of these spaces.
\end{abstract}

Keyword: Musielak-Phy Function, Vector Valued Sequence Space, 2-Normed Spaces

Abstrak. Pada penelitian ini, kami memperkenalkan beberapa ruang barisan bernilai vektor baru atas ruang bernorma-2 menggunakan fungsi Musielak-Phy $\Phi=\left(\varphi_{n}\right)$. Kami juga mempelajari beberapa sifat dari ruang ini.

Kata Kunci: Fungsi Musielak-Phy, Ruang Barisan Bernilai Vektor, Ruang Bernorma-2

Received 16 April 2019 | Revised 20 June 2019| Accepted 12 August 2019

\section{Introduction}

A phy-function, $\varphi$, is a non-negative real valued function on $\mathbb{R}$, which is, continuous, even, nondecreasing function and vanishing at zero. A $\varphi$-function is a generalization of Orlicz function. Using the idea of Orlicz function, $M$, Lindenstrauss and Tzafriri [3] defined the scalar sequence space such that

$$
\sum_{k \geq 1} M\left(\frac{\left|x_{k}\right|}{\rho}\right)<\infty
$$

for some $\rho>0$. This space, denoted by $\ell_{M}$, becomes a Banach space which is called an Orlicz sequence space under the following norm

$$
\|x\|=\inf \left\{\rho>0: \sum_{k \geq 1} M\left(\frac{\left|x_{k}\right|}{\rho}\right) \leq 1\right\} .
$$

*Corresponding author at: Universitas Sumatera Utara, Medan, 20155, Indonesia 
Let $E_{k}$ and $Y$ be Banach spaces. The collection of all bounded linear operators from $E_{k}$ to $Y$ denoted by $B\left(E_{k}, Y\right)$ become a Banach space respected to the following norm

$$
\left\|A_{k}\right\|=\sup \left\{\left\|A_{k} z\right\|: z \in U\left(E_{k}\right)\right\} \text {, }
$$

with $A_{k} \in B\left(E_{k}, Y\right)$ and $U\left(E_{k}\right)$ is the closed unit sphere in $E_{k}$. By $E_{k}^{\prime}$, denotes the collection of all continuous dual of $E_{k}$. Srivastava and Ghosh [6] introduced a class of vector valued sequences using Orlicz-function $M$, i. e. $\ell_{M}\left(B\left(E_{k}, Y\right)\right)$ and $\ell_{M}\left(E_{k}^{\prime}\right)$. They studied Kothe-Toeplitz dual, continuous dual, operator representation and weak convergence for these spaces.

A phy-function, $\varphi$, is said to satisfy convex property, if for every $\alpha, \beta \in[0,1]$ with $\alpha+\beta=1$ and every $x, y \in X$ implies

$$
\varphi(\alpha x+\beta y) \leq \alpha \varphi(x)+\beta \varphi(y) .
$$

The concept of 2-normed spaces was introduced by Gahler [1] in the mid 1960s and many others such as Gunawan and Mashadi [2] have studied and obtained various results.

Let $X$ be a linear space over the field $K$. The function $\|\cdot, \cdot\|: X \times X \rightarrow \mathbb{R}$ is to be a 2-norm on $X$ if it is satisfying the following properties

(1) $\left\|x_{1}, x_{2}\right\|=0$ if and only if $x_{1}$ and $x_{2}$ are linearly dependent.

(2) $\left\|x_{1}, x_{2}\right\|=\left\|x_{2}, x_{1}\right\|$

(3) $\left\|\alpha x_{1}, x_{2}\right\|=|\alpha|\left\|x_{1}, x_{2}\right\|, \alpha \in \mathbb{R}$

(4) $\left\|x_{1}, x_{2}+x_{3}\right\| \leq\left\|x_{1}, x_{2}\right\|+\left\|x_{1}, x_{3}\right\|$ for all $x_{1}, x_{2}, x_{3} \in X$

and the pair $(X,\|\cdot, \cdot\|)$, written as $X_{\|\cdot,\|}$, is called a 2-normed space. For example, we may take $X=\mathbb{R}^{2}$ equipped with the 2 -norm defined as

$$
\left\|x_{1}, x_{2}\right\|_{E}=\left|\operatorname{det}\left(\begin{array}{ll}
x_{11} & x_{12} \\
x_{21} & x_{22}
\end{array}\right)\right| \text {. }
$$

This is the same meaning with the area of the parallelogram spanned by the vectors $x_{1}$ and $x_{2}$. Then, $X_{\|\cdot, \cdot\|}$ is a 2-normed space.

The sequence $\left(x_{k}\right)$ in a 2-normed space $X_{\|\cdot, \cdot\|}$ is said to be converges to $L$ if

$$
\lim _{k \rightarrow \infty}\left\|x_{k}-L, y\right\|=0
$$

holds if for every $y \in X_{\|\cdot, \cdot\|}$. Furthermore, the sequence $\left(x_{k}\right)$ in the arbitrary 2-normed space $X_{\|\cdot,\| \|}$ is called Cauchy sequence if

$$
\lim _{k, p \rightarrow \infty}\left\|x_{k}-x_{p}, y\right\|=0
$$

holds for every $y \in X_{\|\cdot,\|}$. Furthermore, if every Cauchy sequence in the space $X_{\|\cdot,\|}$ converges to some $L \in X_{\|\cdot, \cdot\|}$, then $X_{\|\cdot, \cdot\|}$ is said to be complete respected to the 2-norm. Any complete $n$ normed space is said to be 2-Banach space. 
Let $\Phi=\left(\varphi_{k}\right)$ be a Musielak-Phy function and let $X_{\|\cdot, \cdot\|}$ be a 2-normed space. Let $\Omega\left(X_{\|\cdot, \cdot\|}\right)$ be

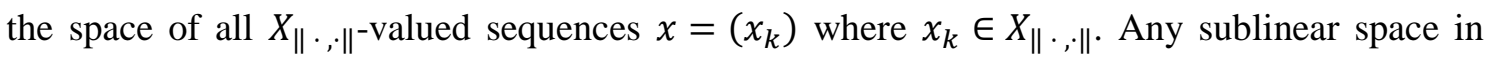

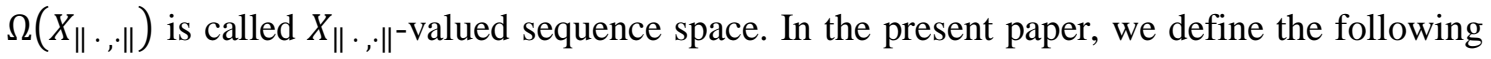
spaces for every $y \in X_{\|\cdot,\|}$ :

$$
\begin{aligned}
& \ell_{1}^{\exists}\left(X_{\|\cdot, \cdot\|}, \Phi\right)=\left\{x=\left(x_{k}\right) \in \Omega\left(X_{\|\cdot, \cdot\|}\right):(\exists \rho>0) \sum_{k \geq 1} \varphi_{k}\left(\left\|\frac{x_{k}}{\rho}, y\right\|\right)<\infty\right\} \\
& \ell_{\infty}^{\exists}\left(X_{\|\cdot, \cdot\|,} \Phi\right)=\left\{x=\left(x_{k}\right) \in \Omega\left(X_{\|\cdot, \cdot\|}\right):(\exists \rho>0) \sup _{k} \varphi_{k}\left(\left\|\frac{x_{k}}{\rho}, y\right\|\right)<\infty\right\} \\
& c_{0}^{\exists}\left(X_{\| \cdot, \cdot, \cdot} \Phi\right)=\left\{x=\left(x_{k}\right) \in \Omega\left(X_{\|\cdot, \cdot\|}\right):(\exists \rho>0) \lim _{k \rightarrow \infty} \varphi_{k}\left(\left\|\frac{x_{k}}{\rho}, y\right\|\right)=0\right\}
\end{aligned}
$$

Throughout this paper, we introduce and study vector valued sequence spaces generated by a Musielak-Phy function over 2-normed spaces.

\section{Results and Discussion}

Theorem 1. Let $\Phi=\left(\varphi_{k}\right)$ be a Musielak-Phy function that satisfy convex property, then the space $\ell_{1}^{\exists}\left(X_{\|\cdot, \cdot\|}, \Phi\right), \ell_{\infty}^{\exists}\left(X_{\|\cdot,\|,}, \Phi\right)$ and $c_{0}^{\exists}\left(X_{\|\cdot, \cdot\|}, \Phi\right)$ are linear spaces over the field of complex numbers $\mathbb{C}$.

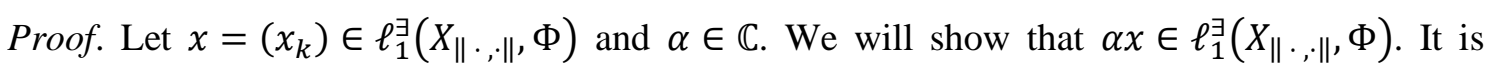
clearly for $\alpha=0$. Assume that $\alpha \neq 0$. Since $x=\left(x_{k}\right) \in \ell_{1}^{\exists}\left(X_{\|\cdot, \cdot\|}, \Phi\right)$, then there exists $\rho>0$ such that

$$
\sum_{k \geq 1} \varphi_{k}\left(\left\|\frac{x_{k}}{\rho}, y\right\|\right)<\infty
$$

Define $\gamma=2 \rho|\alpha|$, then $\frac{|\alpha|}{\gamma}=\frac{1}{2 \rho}$. Thus

$$
\begin{aligned}
\sum_{k \geq 1} \varphi_{k}\left(\left\|\frac{\alpha x_{k}}{\gamma}, y\right\|\right) & =\sum_{k \geq 1} \varphi_{k}\left(\frac{|\alpha|}{\gamma}\left\|x_{k}, y\right\|\right)=\sum_{k \geq 1} \varphi_{k}\left(\frac{1}{2 \rho}\left\|x_{k}, y\right\|\right) \\
& \leq \frac{1}{2} \sum_{k \geq 1} \varphi_{k}\left(\left\|\frac{x_{k}}{\rho}, y\right\|\right)<\infty .
\end{aligned}
$$

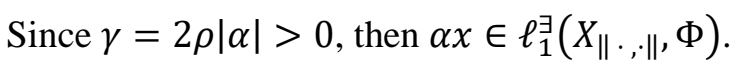

Let $\alpha, \beta \in \mathbb{C}$ and $x=\left(x_{k}\right), z=\left(z_{k}\right)$ in $\ell_{1}^{\exists}\left(X_{\|\cdot,\|}, \Phi\right)$. We will show that

$\alpha x+\beta y \in \ell_{1}^{\exists}\left(X_{\|\cdot,\|}, \Phi\right)$. It is clear if $\alpha=\beta=0$. Assume that $\alpha \neq 0$ or $\beta \neq 0$. Since $x=$ $\left(x_{k}\right), z=\left(z_{k}\right) \in \ell_{1}^{\exists}\left(X_{\|\cdot, \cdot\|}, \Phi\right)$, then there exists $\rho_{1}, \rho_{2}>0$ such that

$$
\sum_{k \geq 1} \varphi_{k}\left(\left\|\frac{x_{k}}{\rho_{1}}, y\right\|\right)<\infty
$$


and

$$
\sum_{k \geq 1} \varphi_{k}\left(\left\|\frac{z_{k}}{\rho_{2}}, y\right\|\right)<\infty
$$

We choose $\rho=\sup \left\{\rho_{1}, \rho_{2}\right\}$. Then

$$
\begin{aligned}
\sum_{k \geq 1} \varphi_{k}\left(\left\|\frac{\alpha x_{k}+\beta z_{k}}{\rho}, y\right\|\right) & \leq \sum_{k \geq 1} \varphi_{k}\left(\frac{|\alpha|}{|\alpha|+|\beta|}\left\|\frac{x_{k}}{\rho}, y\right\|+\frac{|\beta|}{|\alpha|+|\beta|}\left\|\frac{z_{k}}{\rho}, y\right\|\right) \\
& \leq \frac{|\alpha|}{|\alpha|+|\beta|} \sum_{k \geq 1} \varphi_{k}\left(\left\|\frac{x_{k}}{\rho}, y\right\|\right)+\frac{|\beta|}{|\alpha|+|\beta|} \sum_{k \geq 1} \varphi_{k}\left(\left\|\frac{z_{k}}{\rho}, y\right\|\right)<\infty .
\end{aligned}
$$

It means $\alpha x+\beta y \in \ell_{1}^{\exists}\left(X_{\|\cdot,\|}, \Phi\right)$. Hence, $\ell_{1}^{\exists}\left(X_{\|\cdot, \cdot\|}, \Phi\right)$ is a linear space. With the similar way, we can prove that $\ell_{\infty}^{\exists}\left(X_{\|\cdot, \cdot\|}, \Phi\right)$ and $c_{0}^{\exists}\left(X_{\| \cdot, \cdot,}, \Phi\right)$ is a linear space.

Theorem 2. Let $\Phi=\left(\varphi_{k}\right)$ be Musielak-Phy function that satisfy convex property. If $x=\left(x_{k}\right) \in$ $\ell_{1}^{\exists}\left(X_{\|\cdot,\|}, \Phi\right)$ and $y \in X$, then $\ell_{1}^{\exists}\left(X_{\|\cdot, \cdot\|}, \Phi\right)$ become a topological linear spaces that normed defined by

$$
\|x\|=\inf \left\{\rho>0: \sum_{k \geq 1} \varphi_{k}\left(\left\|\frac{x_{k}}{\rho}, y\right\|\right) \leq 1\right\} .
$$

Proof. Firstly, we will show that $\|x\|=0$ if and only if $x=0$. Let $x=0$. Then $x_{k}=0$ for every natural numbers $k$. Thus, for every $y \in X_{\|\cdot, \cdot\|}$ and for every $\varepsilon>0$, we get

$$
\left\|\frac{x_{k}}{\varepsilon}, y\right\|=\|0, y\|=0 .
$$

Since Musielak-phy function, $\Phi$, is vanishing at zero, we have for every $k \in \mathbb{N}$,

$$
\varphi_{k}\left(\left\|\frac{x_{k}}{\varepsilon}, y\right\|\right)=\varphi_{k}(0)=0 .
$$

Therefore

$$
\sum_{k \geq 1} \varphi_{k}\left(\left\|\frac{x_{k}}{\varepsilon}, y\right\|\right)<1 .
$$

It means $\|x\|<\varepsilon$ for every $\varepsilon>0$. Thus $\|x\|=0$.

Let $\|x\|=0$ for every $x \in \ell_{1}^{\exists}\left(X_{\|\cdot,\|,}, \Phi\right)$. We will show that $x=0$.

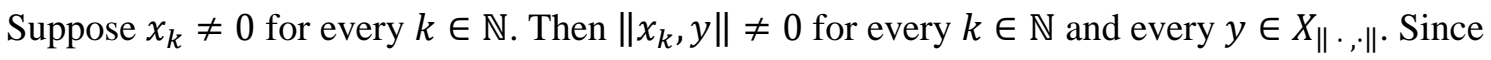
$1 / n \rightarrow 0$ as $n \rightarrow \infty$, then $\left\|n x_{k}, y\right\|=n\left\|x_{k}, y\right\| \rightarrow \infty$. Since $\Phi$ is Musielak-Phy function, then for every $k \in \mathbb{N}$, 


$$
\sum_{k \geq 1} \varphi_{k}\left(\left\|\frac{x_{k}}{1 / n}, y\right\|\right) \rightarrow \infty
$$

This is contrary to the fact that $\|x\|=0$. It should be $x_{k}=0$ for every $k \in \mathbb{N}$ or $x=0$.

Secondly, we will show that $\|\alpha x\|=|\alpha|\|x\|$ for every complex numbers $\alpha$ and $x=\left(x_{k}\right) \in$ $\ell_{1}^{\exists}\left(X_{\|\cdot, \cdot\|}, \Phi\right)$. Since

$$
\|\alpha x\|=\inf \left\{\rho>0: \sum_{k \geq 1} \varphi_{k}\left(\left\|\frac{\alpha x_{k}}{\rho}, y\right\|\right) \leq 1\right\}=\inf \left\{\rho>0: \sum_{k \geq 1} \varphi_{k}\left(|\alpha|\left\|\frac{x_{k}}{\rho}, y\right\|\right) \leq 1\right\}
$$

then, this is clear for $\alpha=0$. Assume that $\alpha \neq 0$. If $\|x\|<\varepsilon$ for every $\varepsilon>0$, then

$$
\sum_{k \geq 1} \varphi_{k}\left(\left\|\frac{x_{k}}{\varepsilon}, y\right\|\right)=\sum_{k \geq 1} \varphi_{k}\left(\left\|\frac{\alpha x_{k}}{\varepsilon|\alpha|}, y\right\|\right) \leq 1 .
$$

Thus, $\|\alpha x\| \leq|\alpha| \varepsilon$. Therefore $\|\alpha x\| \leq|\alpha|\|x\|$.

Since

$$
\|x\|=\left\|\frac{\alpha x}{|\alpha|}\right\| \leq \frac{1}{|\alpha|}\|\alpha x\|
$$

for every $\alpha \neq 0$, implies $|\alpha|\|x\| \leq\|\alpha x\|$. We get, $\|\alpha x\|=|\alpha|\|x\|$.

Finally, take any vector $x, z \in \ell_{1}^{\exists}\left(X_{\|\cdot, \cdot\|}, \Phi\right)$ and $\alpha, \beta \in(0,1]$ such that $\alpha+\beta=1,\|x\|<\alpha$ and $\|z\|<\beta$. Thus, for every $k \in \mathbb{N}$, we get

$$
\varphi_{k}\left(\left\|\frac{x_{k}+z_{k}}{\alpha+\beta}, y\right\|\right)=\varphi_{k}\left(\left\|\frac{\alpha}{\alpha+\beta} \frac{x_{k}}{\alpha}+\frac{\beta}{\alpha+\beta} \frac{z_{k}}{\beta}, y\right\|\right) .
$$

Since $\varphi_{k}$ is a phy-function and it have a convex property implies

$$
\begin{aligned}
& \sum_{k \geq 1} \varphi_{k}\left(\left\|\frac{x_{k}+z_{k}}{\alpha+\beta}, y\right\|\right) \leq \frac{\alpha}{\alpha+\beta} \sum_{k \geq 1} \varphi_{k}\left(\left\|\frac{x_{k}}{\alpha}, y\right\|\right)+\frac{\beta}{\alpha+\beta} \sum_{k \geq 1} \varphi_{k}\left(\left\|\frac{z_{k}}{\beta}, y\right\|\right) \\
& \leq \frac{\alpha}{\alpha+\beta}+\frac{\beta}{\alpha+\beta}=1 .
\end{aligned}
$$

Consequently $\|x+z\| \leq \alpha+\beta$. Thus $\|x+z\| \leq\|x\|+\|z\|$.

\section{Conclusion}

Based on the result section, $\ell_{1}^{\exists}\left(X_{\|\cdot, \cdot\|}, \Phi\right), \ell_{\infty}^{\exists}\left(X_{\|\cdot, \cdot\|}, \Phi\right)$ and $c_{0}^{\exists}\left(X_{\|\cdot, \cdot\|}, \Phi\right)$ are vector valued sequence spaces over 2-normed space with Musielak-phy function $\Phi=\left(\varphi_{k}\right)$ satisfying convex property. Furthermore, for specified norm, $\ell_{1}^{\exists}\left(X_{\|\cdot, \cdot\|}, \Phi\right)$ be a topological linear spaces. 


\section{REFERENCES}

[1] S. Gahler, "2-metrische Raume und ihre topologishe Struktur", Math. Nachr., vol. 26, pp. 115-148, 1963.

[2] H. Gunawan and M. Mashadi, "On n-normed Spaces", International Journal of Mathematics and Mathematical Sciences, vol. 27, no. 10, pp. 631-639, 2001.

[3] J. Lindenstrauss and L. Tzafriri, "Classical Banach Spaces I Sequence Spaces", Springer, Berlin, 1977.

[4] M. Mursaleen, S. K. Sharma and A. Kilicman, "Sequence Spaces Defined by MusielakOrlicz Function over n-Normed Spaces", Abstract and Applied Analysis Hindawi, vol. 2013, 2013.

[5] K. Raj and S. K. Sharma, "Some Sequence Spaces in 2-normed Spaces Defined by Musielak-Orlicz Function", Acta Univ. Sapientiae, Mathematica, vol. 3, no. 1, pp. 97-109, 2011.

[6] P. D. Srivastava and D. K. Ghosh, "On Vector Valued Sequence Spaces $h_{N}\left(E_{k}\right)$, $\ell_{M}\left(B\left(E_{k}, Y\right)\right)$ and $\ell_{M}\left(E_{k}^{\prime}\right)$ ", Journal of Mathematical Analysis and Applications, vol. 327 pp. 1029-1040, 2007. 